the administrator retorted "We don't care if the theories we write about are right, wrong, seriously flawed, downright ignorant or otherwise really, really bad. We only care that the subject is notable." As someone who believes passionately in the value of scholarship, I find this disdain for expert opinion alarming. One hopes that this is an isolated incident, but it does make one wonder whether Google's Knol project or Sanger's Citizendium, which are collecting encyclopaedic articles contributed by named experts, may eventually generate sufficient critical mass to compete with Wikipedia.

Zittrain's book contains more of interest, notably his discussion of 'Privacy 2.0, which includes Scott McNealy's famous quote: "You have zero privacy anyway. Get over it." However, I fear that his concluding example of the One Laptop Per Child project as embodying "both the promise and challenge of generativity" could prove unfortunate if it fails to live up to expectations. He quotes Nicholas Negroponte, the project's founder, as saying "The hundred-dollar laptop is an education project. It's not a laptop project." Negroponte is quoted as saying exactly the opposite in the recent 'resignation' blog of Ivan Krstic, one of the project's early supporters.

Shirky's enjoyable book Here Comes Everybody has insights beyond examples of the power of the web and social networking tools. The collapse of transaction costs for people to join or create groups, he claims, is the driving force behind the Internet revolution. The book describes how mass amateurization has displaced media professionalism, and emphasizes that the web is not merely a new competitor but a whole new ecosystem. Publishers still control the production of print articles and books, but this is increasingly irrelevant now that the costs of print reproduction and distribution have disappeared as a result of the web. On websites such as iStockphoto, photographs by amateurs can be found and purchased as easily as those of professionals, removing any distinction.

Shirky explains how "the difference between communication tools and broadcasting tools was arbitrary, but the difference between conversing and broadcasting is real." Many web postings are tedious because they are meant for a few friends, but the web allows thousands of others to listen in. Shirky discusses how the web is creating new models of organization, yet the arguments are not new - I was reminded of Ricardo Semler's paper on 'Managing Without Managers', published in the Harvard Business Review back in 1989.

Shirky provides the most detailed discussion of the open-source software movement of the three books, although none undertakes a thorough analysis. Shirky states that "Opensource software has been one of the successes of the digital age" and characterizes one of its key features as allowing "failure for free". Software companies need to be conservative and to minimize risk; by contrast, the open-source community can explore a vast landscape of different ideas. Leadbeater believes the community behind development of the Linux operating system is "the most impressive example of sustained We-Think", although he acknowledges the paradox of companies such as Google, IBM and HP making money using open-source software. All three authors subscribe to the idea that open-source software is produced by an unpaid army of volunteers from around the world. The situation is not so simple.

Open-source projects can be divided into two clusters, 'money-driven' and 'communitydriven', according to a 2006 paper by Marco Iansiti and Gregory L. Richards of Harvard Business School. The first type has received billions of dollars in investment from vendors over the past decade; for example, more than $70 \%$ of the Linux kernel development is carried out by professional software developers. Community-driven open-source projects constitute well over $95 \%$ of the 150,000 or so projects in the SourceForge open-source software repository, but the vast majority of these have a handful of users and developers. Nonetheless, Shirky points out, the tendency of open-source projects to fail is also the movement's strength: "Open source is a profound threat, not because the open-source ecosystem is outsucceeding commercial software but because it is outfailing them."
Leadbeater's We-Think is the least convincing book. He gives interesting examples of social networks and a fascinating survey of the origins of 'We-Think', attributing the idea to pioneers such as Doug Engelbart, inventor of the computer mouse, the electronics enthusiasts of Silicon Valley's Homebrew Computer Club and radical philosophers such as Ivan Illich. Leadbeater claims that the web has the potential to "spread democracy, promote freedom, alleviate inequality and allow us to be creative together" and claims that "community and conversation are the roots of creativity". Yet I find it difficult to take seriously his basic premise that mass participation will generate collaborative creativity. I concede that collaboration between specialists will become more important as we attack challenging global problems. In my experience, creativity and inspiration are the rare gifts of individuals, following much scholarship and hard work. Although I would like to think that the web will change the world for the good - and I am sure that it will in some ways - it seems naive to think that it will cause a fundamental change in human nature.

These three books contain much that is perceptive, informative and downright silly, much like the Internet itself. It is this 'generativity' that they celebrate.

Tony Hey is Corporate Vice President for External Research, Microsoft Research, One Microsoft Way, Redmond, Washington 98052, USA. e-mail: tony.hey@microsoft.com All opinions in this review are personal and do not represent the views of the Microsoft Corporation.

\title{
Virtual similarities
}

\author{
Coming of Age in Second Life: \\ An Anthropologist Explores \\ the Virtually Human \\ by Tom Boellstorff \\ Princeton University Press: 2008. 328 pp. \\ $\$ 29.95, \notin 17.95$
}

In his book Secondary Worlds, W. H. Auden wrote that "present in every human being are two desires, a desire to know the truth about the primary world ... and the desire to make new secondary worlds of our own or, if we cannot make them ourselves, to share in the secondary worlds of those who can". Auden, in 1968, was writing about literature, not cyberspace, but his thoughts help explain why virtual worlds are popular today.

The conflicts that arise from this desire to live in both a primary world and a secondary world removed from physical reality are examined in Coming of Age in Second Life. Anthropologist Tom Boellstorff paints an ethnographic portrait of the online virtual world, Second Life, that is fully immersed in its subject. To prove that virtual worlds are cultures in their own right, Boellstorff conducted all his research from within Second Life, using the ethnographer's toolkit of interviews, focus groups and participant observation. Unlike other studies that take an outside perspective, he made no attempt to make real-life contact with his fellow residents.

Some may argue that it is not possible to 
understand a person's virtual life without knowing their actual-life history. Online, residents can mask their identity, including their race, gender and age. Some adopt multiple virtual bodies - avatars - and some avatars are controlled by more than one person. Does Boellstorff's approach have any value? The author argues that residents have created a culture in which it is not necessary to know a person's true identity to engage in meaningful interactions. To understand how these relationships work, an anthropologist should not need any additional information, and behaviours can be better examined from the same viewpoint as the subjects of the study.

The gap between the virtual and the physical, and its effect on the ideas of personhood and relationships, is the most interesting aspect of Boellstorff's analysis. For many residents, having a separate embodiment in cyberspace is liberating. There, they are free to be the people they imagine themselves to be, no longer held back by real attributes or attitudes. This liberation was evident in transgender people experimenting with a new lifestyle in Second Life before making decisions in the actual world.

Freedom is the primary attraction for many residents. When Linden Lab, the software company behind Second Life, pondered whether to introduce voice communication to the platform, in addition to the existing textual chat, it provoked widespread riots within the virtual world. The sound of a real voice would have closed the gap between the real person and the virtual avatar to an unacceptable degree.

The real-virtual disparity can bring a painful

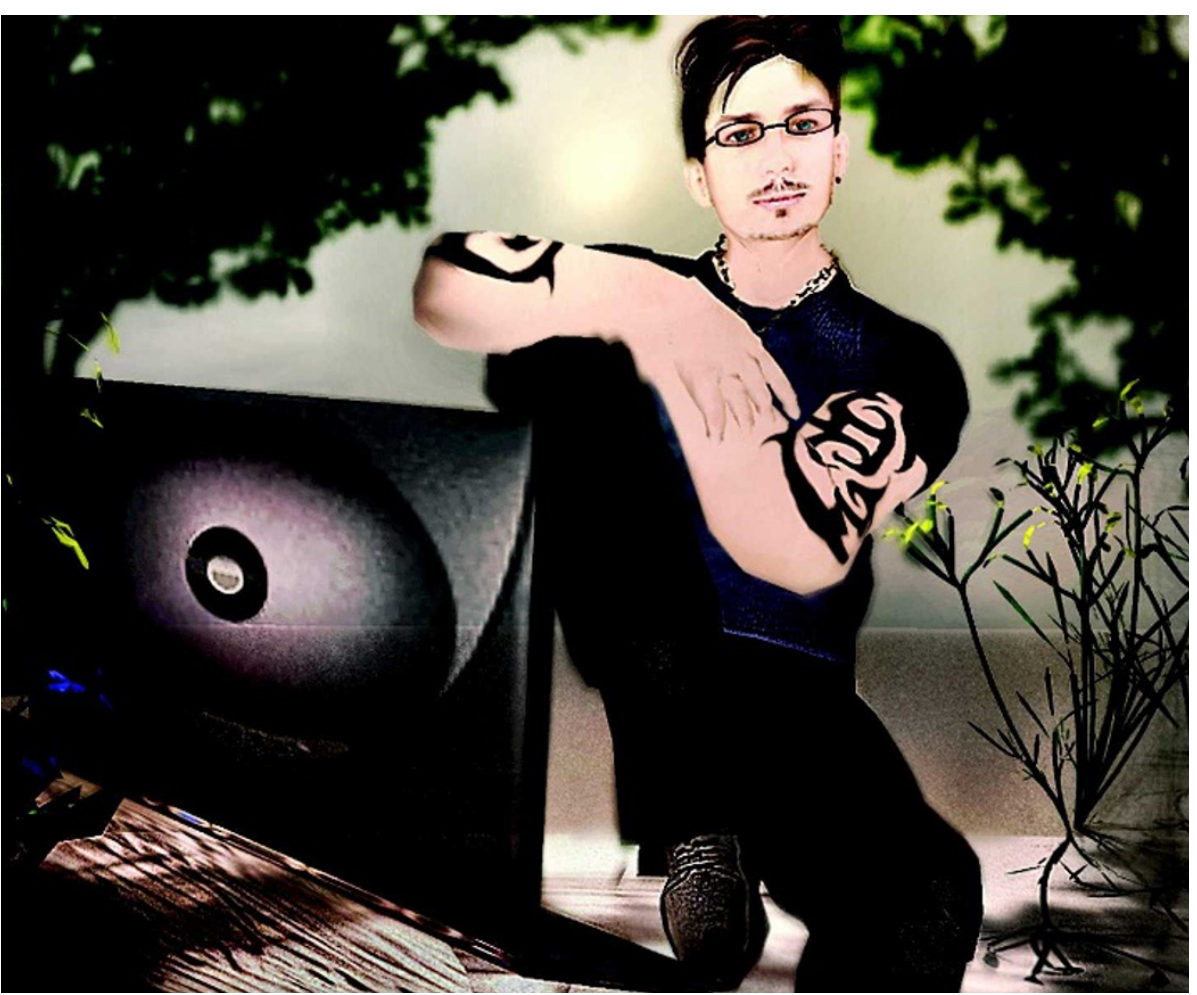

Tom Boellstorff's anthropologist avatar carries out his research within the virtual world.

distance between virtual friends or lovers. Boellstorff writes of Susan and George, who enjoyed a close relationship conducted solely in the virtual world for a year and a half. When George failed to log in for a whole month, Susan's devastation was real. He may have died in the real world, or might have simply tired of the relationship, but without knowing his true identity, Susan was powerless to find out. Many commentators question the

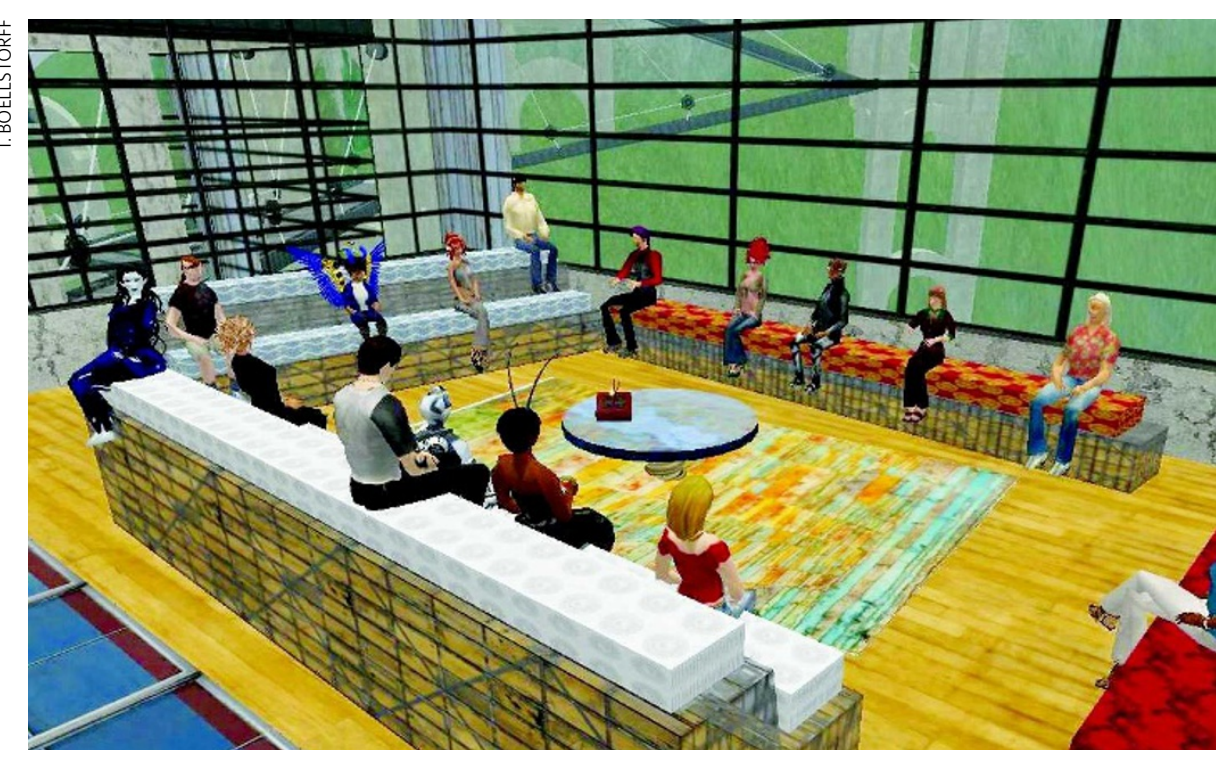

Focus groups revealed that virtual relationships were just as important as physical ones. existence of meaningful relationships within virtual worlds, but Boellstorff demonstrates that the emotional commitment invested makes them just as real and worthy of study.

A portrait of Second Life would not be complete without documenting the more colourful members of its society, such as the 'furries' who are embodied in animal avatars or the virtual sex workers. Given the popular media coverage of Second Life, it would have been easy to focus on these sensational residents, but the closer study of more mundane characters such as Susan and George provides valuable insights. Boellstorff shows that although Second Life culture has its own unique nuances, for the majority of residents it is no more surprising than societies based in the physical world.

During the period of Boellstorff's study, June 2004 to January 2007, the population of Second Life grew from a few thousand to several million, with important software upgrades along the way. Technology moves quickly, and the society portrayed in Coming of Age in Second Life may change in the future. Boellstorff's portrayal of a virtual culture at the advent of its acceptance into mainstream life gives it lasting importance, and his methods will be a touchstone for research in the emerging field of virtual anthropology.

David Robson is a writer based in London, UK. e-mail:d_a_robson@hotmail.com 